\title{
ASPECTOS ESTRUTURAIS DOS LIVROS DIDÁTICOS DE PORTUGUÊS: UM OLHAR AO LONGO DO TEMPO
}

Luciene Maria Patriota*

\begin{abstract}
Resumo: Muitos aspectos dos Livros Didáticos de Português (LDP) podem nos levar a importantes reflexões, principalmente no âmbito de análises longitudinais. Logo, o objetivo deste artigo, de base bibliográficadocumental, é mostrar as mudanças estruturais dos LDP em seus aspectos visuais-tipográficos ao longo do tempo, como forma de se pensar como os fatos históricos motivam e condicionam a sua organização. Para isso, selecionamos estudiosos que se debruçam sobre os LDP, na busca pela construção de um perfil ao longo dos séculos. As diversas mudanças estruturais revelam que os LDP se adaptam a cada momento histórico e revelam em seus aspectos visuais-tipográficos, as transformações sofridas na sociedade e que repercutem diretamente sobre formatos, estruturas e conteúdos que circulam nesses livros.
\end{abstract}

Palavras-chave: Ensino. História. Livro Didático de Português.

\begin{abstract}
When analyzing aspects of Portuguese Language Textbooks (PLT), relevant insights can be achieved. Based on that, this paper aims to demonstrate the structural changes of PLT concerning their visualtypographical aspects over time as a way of thinking how the historical facts motivate and adjust the organization of these books. Scholars who address the LDP and their profile over the centuries were chosen to base this work. As a result, it was unveiled that even in facing so many structural changes, the PLT have never ceased to exist or to be recognized. These changes actually reveal that these books are adapted to each historical moment and simultaneously reveal the changes undergone in society through the formats, structures and contents of these books.
\end{abstract}

Keywords: Education. History. Portuguese Language Textbooks.

\section{Introdução}

A cultura escolar desde sempre revelou em sua história a presença de materiais destinados ao ensino. Como nos mostram Batista, Galvão e Klinke (2002), esses materiais eram representados por textos manuscritos, documentos de cartório, cartas, a Constituição do Império, o Código Criminal, a Bíblia, que eram usados para fins didáticos, voltados ao trabalho com leitura.

Segundo esses estudiosos, só a partir da segunda metade do século XIX foi que começaram a surgir os primeiros livros nacionais de leitura destinados ao ensino. Esses livros foram evoluindo até chegarem ao que hoje denominamos livros didáticos.

Sendo assim, discutir sobre esses livros, seja em que esfera for, é uma atividade que não pode estar desvinculada da associação dos LD com o sistema educacional, no nosso caso específico, o brasileiro. A trajetória histórica de um está intrinsecamente ligada a do outro, podemos até mesmo afirmar, sem medo de incorrer numa inverdade, que escola e ensino não existem sem a "figura" do livro didático e vice-versa. Nas palavras de Pessanha et al (2004):

$\mathrm{Na}$ escola foram sendo historicamente construídas normas e práticas definidoras dos conhecimentos que seriam ensinados e dos valores e conhecimentos que seriam inculcados, gerando o que se pode chamar de cultura escolar. Conhecimentos, valores e comportamentos que, embora tenham assumido uma expressão peculiar na escola, e, principalmente, em

\footnotetext{
* Doutora em Linguística pela Universidade Federal da Paraíba, Mestre e Especialista pela Universidade Federal de Campina Grande, professora-adjunta da Universidade Federal de Campina Grande. Endereço eletrônico: ene.patriota@yahoo.com.br.
} 
cada disciplina escolar, são produtos e processos relacionados com as lutas e os embates da sociedade que os produziu e foi também produzida nessa e por essa escola (PESSANHA et al, 2004, p. 58).

Portanto, compartilhando da opinião de Freitag (1989, p. 25), estamos partindo, nesse artigo, do "pressuposto básico de que o estudo do livro didático não pode ser feito isoladamente, focalizando-se o livro didático em si”. Mas, acreditamos que é numa perspectiva histórica que podemos encontrar respostas para o porquê de esses livros circularem na escola, o porquê de sua estrutura, o porquê dos conteúdos que veicula, o porquê de suas mudanças, o porquê de seus traços de permanência. E, a partir do percurso histórico dele, entender a própria história social do português do Brasil, relacionado à educação. Compartilhamos também da opinião de Oliveira (1984) para quem:

A importância do livro didático não se restringe aos seus aspectos pedagógicos e às suas possíveis influências na aprendizagem e no desempenho dos alunos. O livro didático também é importante por seu aspecto político e cultural, na medida em que reproduz e representa os valores da sociedade em relação à sua visão da ciência, da história, da interpretação dos fatos e do próprio processo de transmissão do conhecimento (OLIVEIRA, 1984, p. 11).

Ele reflete, pois, as mudanças históricas/sociais da sociedade, da escola, do ensino ao longo do tempo. Partindo dessa premissa, seguimos agora a trilha histórica, refazendo a trajetória do Livro Didático de Português, enfocando, essencialmente, os aspectos visuaistipográficos deles.

\section{Percurso histórico dos livros didáticos de português - dimensão visual-tipográfica}

Uma vez que através desse tópico nos propomos recuperar a trajetória seguida pelos LDP ao longo dos séculos XX e XXI, consideramos oportuno iniciar esse percurso com uma breve história da disciplina alvo dos livros por nós analisados: a língua portuguesa.

Em termos de língua, o que existia em nosso país nos seus primórdios era o que se denominava língua-geral ${ }^{1}$ e latim, que conviviam lado a lado com o português trazido pelo colonizador. Das três, era a língua-geral que prevalecia nas atividades cotidianas da colônia e os trabalhos de catequese realizados pelos jesuítas. Nas palavras de Soares (2002):

Com a língua-geral evangelizavam os jesuítas, nela escreveram peças dramáticas para a catequese; era ela que os bandeirantes falavam, com ela é que nomearam flora, fauna, acidentes geográficos, povoações; foi ela quase sempre a língua primeira das crianças, dos filhos tanto dos colonizadores quanto dos indígenas (SOARES, 2002, p. 158).

E assim o foi até os anos 1950 do século XVIII, quando, por determinação do Marquês de Pombal, o português foi instituído língua obrigatória, com a proibição do uso de todas as línguas antes usadas na colônia. A ênfase do ensino passou a ser, juntamente com o estudo da gramática latina, aprender a ler e a escrever em português, com a introdução do estudo da gramática portuguesa. Com isso, até o fim do século XIX, dois componentes foram privilegiados nas escolas: a retórica e a gramática (MATTOS e SILVA; SOUZA, 2009).

\footnotetext{
${ }^{1} \mathrm{Na}$ verdade, ela recebia o nome de língua-geral, mas, na realidade, não era apenas uma língua, mas várias.
} 
Nesse contexto, as cartilhas, os manuais, ortografias foram trazidas nas navegações com o intuito de fixar a língua.

Esse fundo histórico (embora breve!) é essencial, a nosso ver, para entendermos "o caminhar" do LDP ao longo dos séculos. Isso porque, diferente do que se pensa, esses livros não são exclusividade da contemporaneidade, mas sempre estiveram presentes no ambiente escolar, sendo influenciado diretamente pelos fatos históricos, sociais, culturais vigentes em cada época (SOARES, 1996; RAZZINI, 2001).

Antes, porém, de seguirmos mostrando a dimensão visual-tipográfica dos LDP nas décadas por nós delimitadas, achamos oportuno reproduzir uma citação de Soares, embora se trate de uma citação de nove anos atrás, consideramos seu teor muito atual e pertinente para o que estamos nos propondo realizar aqui. Diz essa autora:

Muitos e vários olhares vêm sendo lançados sobre o livro didático nos últimos anos: um olhar pedagógico, que avalia qualidade e correção, que discute e orienta a escola e o uso; um olhar político, que reformula e direciona processos decisórios de seleção, distribuição e controle; um olhar econômico, que fixa normas e parâmetros de produção, de comercialização, de distribuição. Avaliar qualidade e correção, orientar escolhas e uso, direcionar decisões, fixar normas... são olhares que prescrevem, criticam ou denunciam; por que não um olhar que investigue, descreva e compreenda? Olhar que afaste o "dever ser" ou o "fazer ser" e volte-se para o "ser" - não o discurso sobre o que "deve ser" a pedagogia do livro didático, a política do livro didático, a economia do livro didático, mas o discurso sobre o que "é", o que "tem sido", o que "foi” o livro didático (SOARES, 1996, p. 53).

É o chamado "olhar sócio-histórico" sobre o livro didático, termo usado por Soares, o que desenvolveremos aqui a partir dos seus aspectos visuais-tipográficos, tendo como meta central, observar como os fatos históricos influenciam mudanças nesses livros em todos os momentos históricos. Isso quer dizer que mudanças no quadro histórico vão repercutir diretamente nos livros, modificando-o, tanto internamente, como externamente.

No aspecto formal, estrutural, portanto, consideramos relevantes as mudanças ocorridas no formato, capas, diagramação/organização interna dos livros e titulação, visto serem aspectos diretamente influenciados pelo momento histórico de circulação de cada livro.

Nesse aspecto, percebemos o LDP como uma estrutura marcadamente fixa e institucional, ou seja, mesmo com todas as modificações ao longo dos séculos, ele segue um padrão que, apesar das inovações sofridas, não se descaracteriza enquanto livro didático, mas tais mudanças, ao longo do tempo, nos fornecem pistas que nos fazem entender os fatos históricos e linguísticos revelados em tais modificações.

É o "olhar" que busca o "ser", o "que é", o "que foi" o livro didático de português. Remetendo-nos à citação de Soares, sem pretensões prescritivas, avaliativas, mas unicamente de compreensão deles.

\subsection{Primeiras décadas do século $\mathrm{XX}$}

Para as primeiras décadas do século $\mathrm{XX}$, temos, em relação ao Livro Didático de Português, olhares diversos. De acordo com Batista (2004) e Soares (2002), no que se refere à questão das dimensões, capas, diagramação e titulação, ao longo dos séculos os LDP apresentaram muitas mudanças. Aproximadamente, até a década de 1950 do século XX, 
grande parte dos livros apresentavam o tamanho $17 \times 11 \mathrm{~cm}$, em média, com capas e layout sóbrios, sem a presença de cor. Predominava a sobriedade. O que prevalecia era a cor cartonada com detalhes em preto e branco. Conforme vemos na Fig. 1:

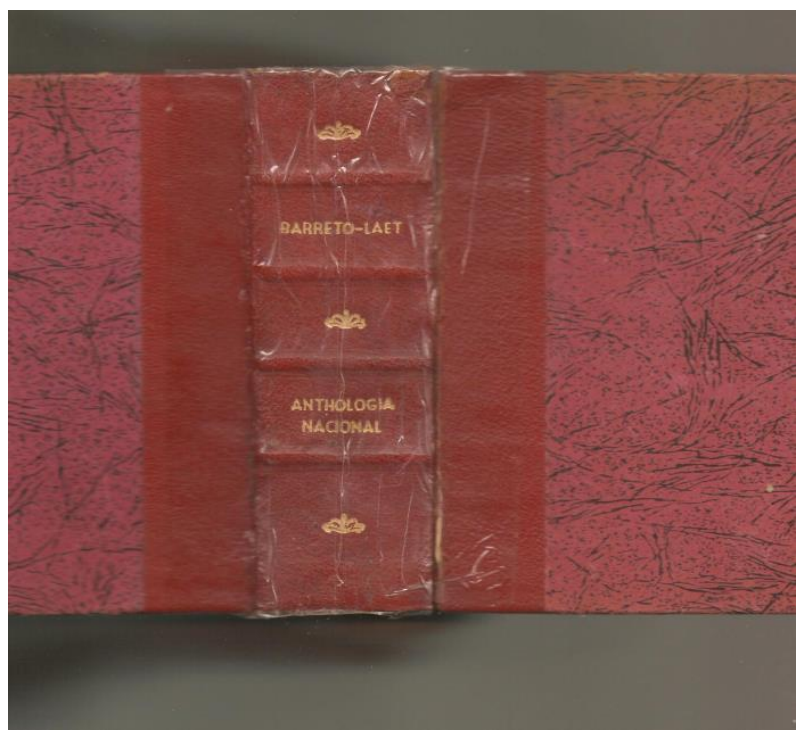

Figura 01 - Capa da Antologia Nacional

Fonte: Barreto; Laet, 1921

Internamente eram livros representados pelas seletas de textos, geralmente organizadas em Antologias, sem nenhum tipo de exercício, com trabalho complementar a partir de gramáticas. Quanto à titulação, predominavam títulos como Antologia, Língua Portuguesa, Língua Pátria, Português para o Ginásio, Gramática Elementar, etc.

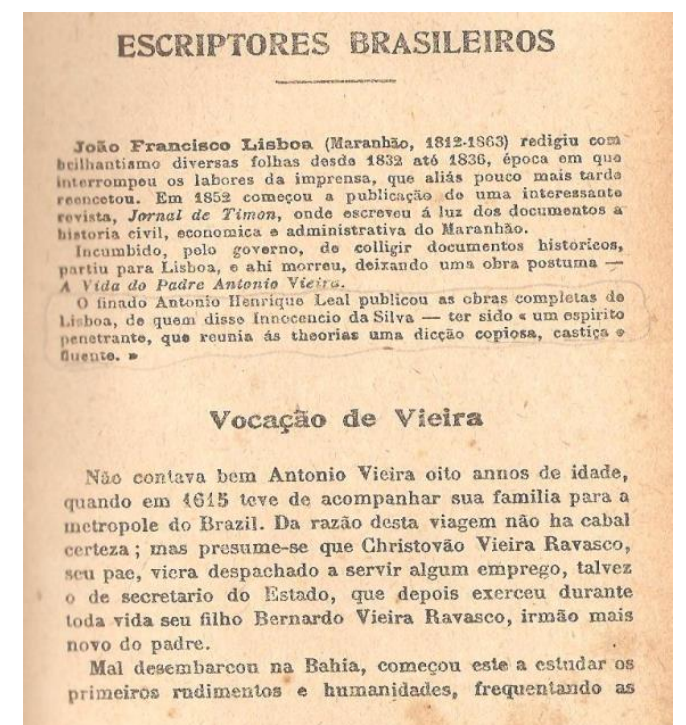

Figura 02 - Parte interna da Antologia Nacional Fonte: Barreto; Laet, 1921

Trata-se de uma rigorosa seleção de textos para leitura, não há oferta de nenhum exercício, marca característica das antologias que circulavam nesse período. Todo conteúdo era organizado num só livro com 602 páginas em média, traço completamente diferente dos LDP das décadas seguintes.

Historicamente, segundo Soares (2002) e Batista (2004), toda essa estruturação está ligada à própria história da disciplina português vista anteriormente. Esses livros existiam 
para enfatizar os estudos gramaticais, retóricos e poéticos, seguiam toda uma tradição voltada para os "bons usos" da língua, dirigidos aos filhos das classes favorecidas social e economicamente. Como bem assinala Soares (2002), se referindo a essa época:

Embora a disciplina curricular se denominasse português, persistiam embutidas nela as disciplinas anteriores, até mesmo com individualidade e autonomia, o que se comprova pela convivência na escola, nas cinco primeiras décadas do século XX, de dois diferentes e independentes manuais didáticos: as gramáticas e as coletâneas de textos (SOARES, 2002, p. 165).

No entanto, diferente da perspectiva de Soares (2002) e Batista (2004), outros estudos nos mostram que as primeiras décadas do século XX já apresentavam versões de LDP bem diferentes do modelo descrito por eles. Segundo Oliveira e Souza (2011) e Silva (2011), tratavam-se de livros de leitura com um perfil totalmente diferente do seguido pela Antologia Nacional.

Eram livros destinados às escolas primárias públicas ${ }^{2}$ e tinham tamanho médio ${ }^{3}$, com capas coloridas, com diversas gravuras relacionadas aos temas a serem estudados. Eram organizados por série, que representavam os níveis de ensino - elementar, médio e superior. Além disso, traziam exercícios no interior das lições, destinados à fixação tanto das primeiras letras, como da compreensão dos textos em estudo. Como vemos na Fig. 03.

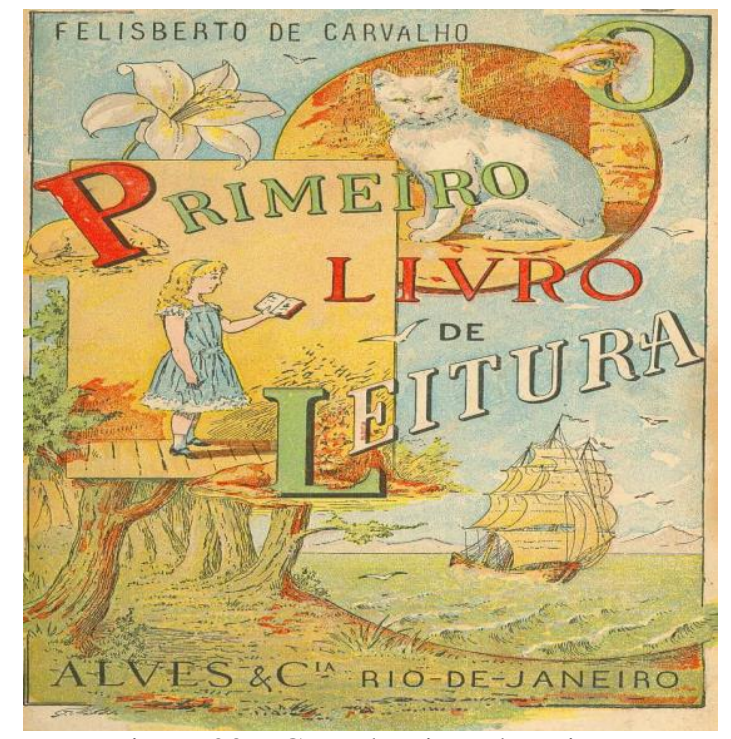

Figura 03 - Capa do Livro de Leitura

Fonte: Carvalho, 1911

Outra referência a esse período é Farias (2010). Nela, ele analisa a Coleção Novo Manual de Língua Portuguesa F.T.D. Segundo ele, essa coleção permaneceu nas escolas brasileiras da primeira década do século XX, até a década de 1940. O Novo Manual também seguia uma gradação de cursos e faixas etárias que abarcavam o ensino primário e secundário. Apresentavam exemplares do aluno e do mestre, exercícios e também ilustrações, tanto abrindo as unidades, como também no interior dos livros.

Sendo assim, diante do exposto, as décadas de 1950/1960 do século XX, tomadas por Soares (2002) e Batista (2004) como representativas da chegada do que eles denominaram

\footnotetext{
${ }^{2}$ Importante ressaltar aqui que até a década de 1930 predominava em nosso país o ensino dual, representado pelas escolas primárias e secundárias.

${ }^{3}$ As autoras não mencionam o tamanho exato que denominaram de "médio".
} 
"novo livro", foram, na verdade décadas que começaram a consolidar um modelo que já circulava nas escolas, mesmo que com número representativo ainda pequeno.

\subsection{As décadas de 1970/1980}

Uma vez que, como vimos, nas primeiras décadas de século XX já encontrávamos livros com o formato descrito por Soares (2002) e Batista (2004) para o chamado novo livro, consideramos essa nomenclatura problemática. Diante disso, achamos mais conveniente nos referirmos a essas décadas com o termo consolidação de um modelo já existente e essa motivada pelos fatos históricos levantados por Soares (2002). Entre esses fatos:

1) A progressiva transformação das condições sociais;

2) O acesso dos filhos dos trabalhadores à escola;

3) A deteriorização da profissão-professor;

4) O fato de os componentes gramática e texto começarem a constituir-se conteúdo articulado.

Foram, em essência, esses novos fatos históricos que consolidaram oformato do LDP, que explodiu, digamos assim, com maior ênfase, no final da década de 1960, início de1970 do século passado. Suas dimensões passaram a ser $21 \times 14 \mathrm{~cm}$, ainda diferente do formato atual, mas já maior que os livros predominantes até a década de 1950. As capas eram, à princípio, plastificadas, com duas cores, algumas vezes essas cores diferenciando as séries, visto os livros agora serem definitivamente organizados por série, como permanecem na atualidade.

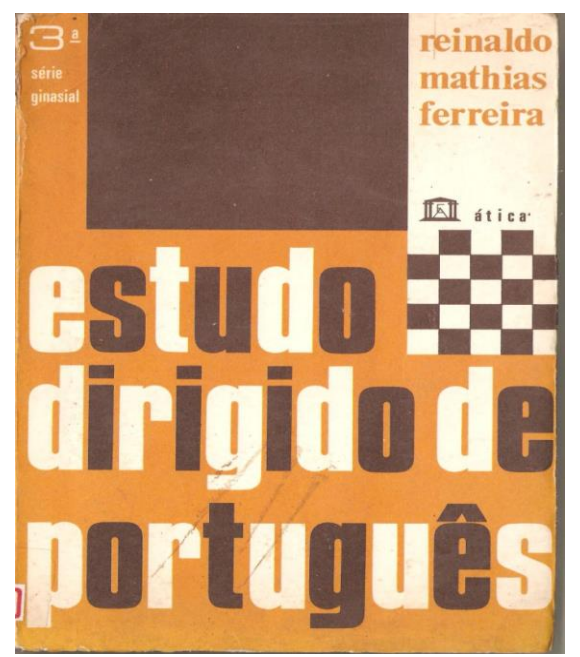

Figura 04 - Capa do Estudo Dirigido de Português Fonte: Ferreira, 1971

Internamente, as mudanças foram progressivas, com a introdução de ilustrações, palavras-cruzadas, caça-palavras, jogos, quadrinhos e toda uma seleção de textos voltados para atrair o interesse do aluno. Com o passar do tempo, essas inovações foram se intensificando cada vez mais, chegando os LDP a serem denominados por Lins (1977) de Disneylândia pedagógica. 


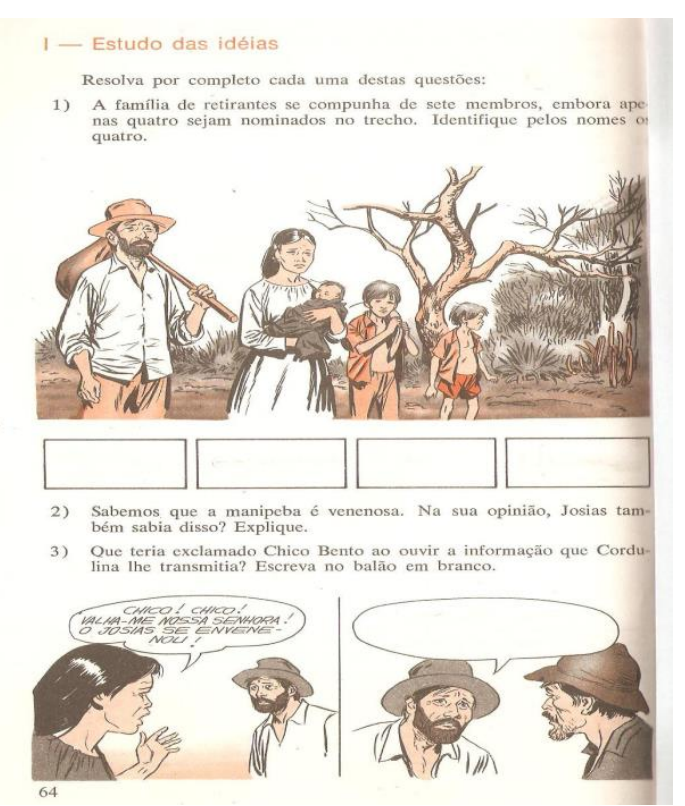

Figura 05 - Parte interna do Estudo Dirigido de Português Fonte: Ferreira, 1971.

Todos os livros da coleção trazem ilustrações iniciando as seções de estudo tanto dos textos, quanto gramaticais, sendo que nas primeiras edições essas ilustrações apenas abrem as seções de estudo, variando as cores em cada série: vermelho na $6^{\mathrm{a}}$ série, azul na $7^{\mathrm{a}}$. Nas edições seguintes, as ilustrações já aparecem ao longo da unidade e não apenas no início, como pudemos verificar no livro da $8^{\mathrm{a}}$ série, $13^{\mathrm{a}}$ edição. A cor predominante nessa edição foi o laranja.

Na década de 1970, ainda era comum os livros apresentarem-se divididos em duas partes: a primeira com uma seleção de textos e suas respectivas atividades de compreensão; a segunda com uma seleção dos tópicos gramaticais a serem estudados em cada série. Cada uma com extensa oferta de exercícios, tanto destinados ao trabalho com os textos, como para os tópicos gramaticais. Todo trabalho de leitura e gramática ainda era realizado de forma não articulada.

Um detalhe importante é que os livros nesse período eram todos consumíveis, ou seja, com espaço em branco nas atividades para as respostas dos alunos, fato que não permitia reaproveitamento posterior deles. É também nesse período que os livros do professor passam a circular com maior frequência. ${ }^{4}$

\footnotetext{
${ }^{4}$ Não nos aprofundaremos em questões relativas ao livro do professor e suas mudanças históricas, consideramos que esses livros já dariam outra discussão com dimensões de análise voltadas diretamente para o professor.
} 


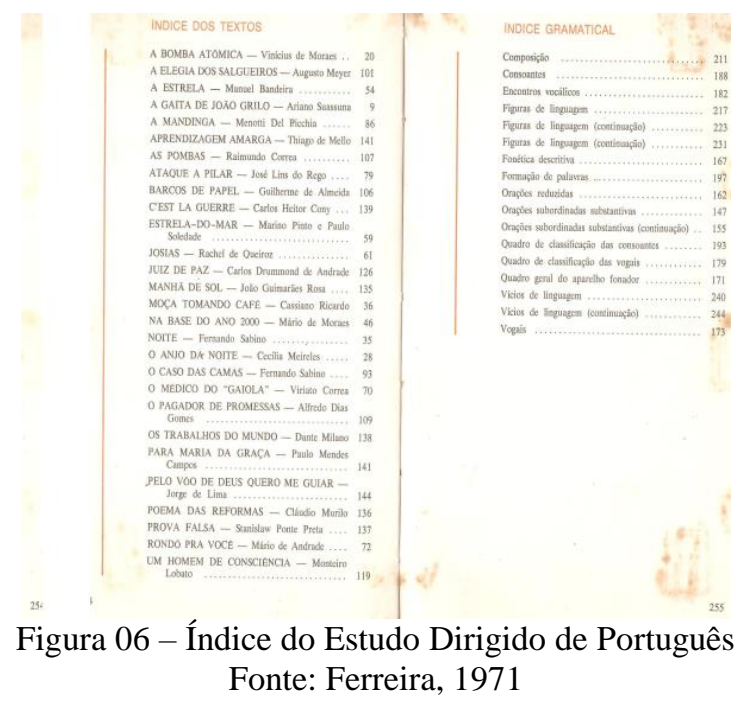

\subsection{A contemporaneidade}

Antes de seguirmos com o percurso dos LDP, nos detendo nos chamados livros contemporâneos, que abarcam a década de 1990 do século XX até nossos dias atuais, consideramos de extrema importância tecer algumas considerações relativas ao papel da década de 1980 para o atual formato dos LDP.

Nessa década, os LDP passaram a figurar muito mais como objeto de estudo de numerosos pesquisadores. Vários aspectos desses livros foram alvo de análises, severas críticas, indo desde os aspectos gráficos, até questões relativas à ideologia, aspectos linguísticos, literários, didáticos, psicológicos, sociais. Foi uma década não de alterações nos conteúdos ou na estrutura dos livros, mas de estudos voltados aos conteúdos neles presentes à luz das novas teorias linguísticas, entre elas a Linguística Textual, a Sociolinguística, a Pragmática e a Análise do Discurso.

Um outro enfoque desses estudos, segundo Batista; Rojo (2005) e Bezerra (1993), tinha o cunho de denúncia contra preconceitos de raça, cor, gênero e conteúdos ideológicos que veiculavam livremente nos LDP em circulação. Foi uma década, portanto, de muita produção acadêmica sobre os livros, mas não de alteração neles, que culminou em fatos essenciais para o formato atual desses livros. De acordo com Dionísio; Bezerra (2002) e Oliveira (2008), podemos elencar:

1) A entrada da concepção de língua como interação nos LDP;

2) Os novos programas do governo destinados à avaliação do livro didático - o PNLD - 1996;

3) A divulgação dos Parâmetros Curriculares Nacionais destinados ao Ensino Fundamental - 1997.

De acordo com Pietri (2008), foi também nessa década que explodiu nos meios acadêmico e não-acadêmico o que se convencionou chamar de Discurso da Mudança discussões desenvolvidas no final da década de 1979 e na década de 1980 que visavam não só integrar as ideias desenvolvidas pelos linguístas ao ambiente escolar - especialmente professores, mas que, a nosso ver, também tinham relação direta com as questões relacionadas aos LDP - propondo mudanças radicais nas concepções de linguagem e no ensino de língua materna, mas também amenizar as fortes críticas recebidas pela Linguística na época. Nas palavras de Pietri (2008): 
O produto da prática científica não é apenas levado ao conhecimento de um leitor caracterizado como alguém desejoso de conhecer as novidades que a ciência tem a lhe apresentar, mas o conhecimento científico deve convencer esse leitor sobre a necessidade de transformar suas concepções de linguagem e de ensino de língua materna. Esse novo discurso é não apenas pedagógico, mas argumentativo: procura convencer quanto à necessidade de alterar o ensino corrente, substituí-lo por um ensino não discriminatório, transformador (PIETRI, 2008, p. 838).

Esse movimento e todos osfatos históricos elencados anteriormente foram determinantes para a estruturação dos LDP, que passaram a apresentar dimensão em torno de $28 \times 19 \mathrm{~cm}$, com capas cada vez mais ricas em colorido, imagens, ilustrações, sugerindo a dinamicidade do mundo atual. Muitas informações a cada momento se renovando, sendo repassadas aos livros através de um layout moderno com várias ilustrações que perpassam todo o livro, toda a unidade didática. Foi nesse período que os livros didáticos passaram a ser obrigatoriamente não-consumíveis, ou seja, sem espaços para respostas dos alunos, visando sua reutilização. A Fig. 07 mostra esse momento dos livros:

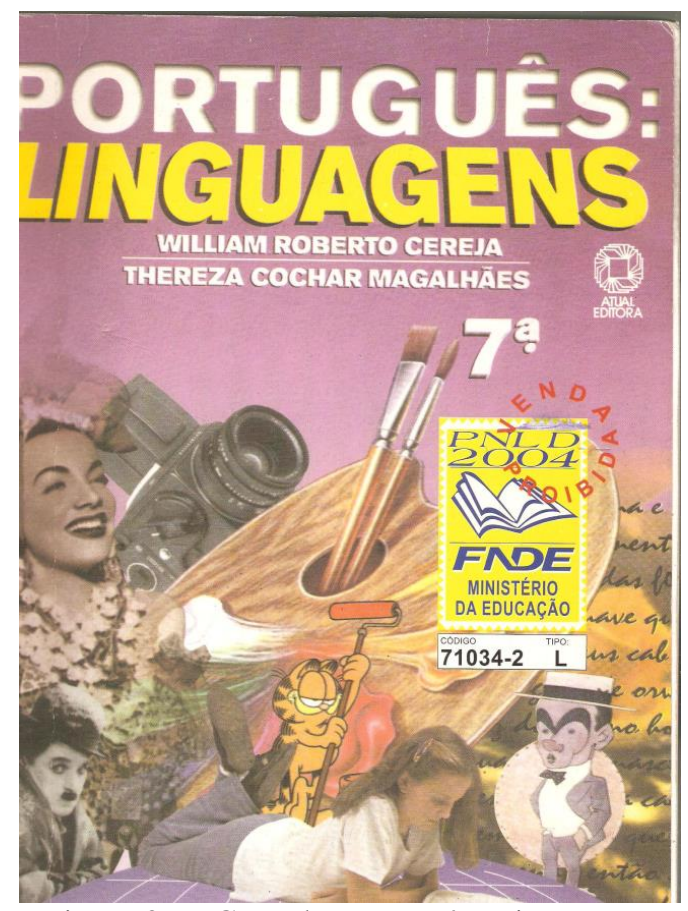

Figura 07 - Capa do Português: Linguagens Fonte: Cereja; Magalhães, 1998.

Além de cruzadas, jogos, quadrinhos, sugestões de filmes, CDs, DVDs, sites relativos aos temas abordados nas unidades são introduzidos nos livros, refletindo a dinamicidade do mundo moderno e o convívio dos LDP com a era virtual, característica dos anos atuais (MARCUSCHI, 2005; COSCARELLI; CORRÊA, 2009).

Sousa (2006), analisando um livro didático contemporâneo, destinado ao ensino médio, nos apresenta uma descrição desses livros bastante fiel à forma como eles são estruturados. Acreditamos ser válido reproduzir aqui tal descrição:

(...) Há muitos, diversificados e bons textos. Numa única páginado livro, o leitor se depara com uma multiplicidade de informações: charges, letras de 
músicas, sugestões sobre filmes, livros, músicas, sites. Contudo, são peças de um mosaico, cujas cores, disposição, arranjos, nem sempre compõem uma figura que agrada aos olhos, acalma a mente e sossega o coração do leitor (...) mas, de qualquer maneira, é preciso admitir que essa arrumação dos textos nas páginas do livro traduz exatamente essa ideia do sujeitomoderno-ilha, rodeado de linguagens por todos os lados, sem margens para fugir (SOUSA, 2006, p. 226).

Um livro que reproduz a dinâmica movimentada e sempre em mudança do novo milênio. É esse movimento intenso de cores e ilustrações que fazem, a nosso ver, os LDP contemporâneos diferirem dos das primeiras décadas do século XX. Nas décadas iniciais do século XX, o colorido, quando aparecia, era mais lúdico, sem essa ideia de multiplicidade/movimento intenso de informações presentes nos livros atuais.

Internamente, os livros são organizados por unidades temáticas, com o estudo conjunto dos textos e tópicos gramaticais já consolidados numa mesma unidade, sem a divisão clássica das décadas anteriores entre texto e gramática.

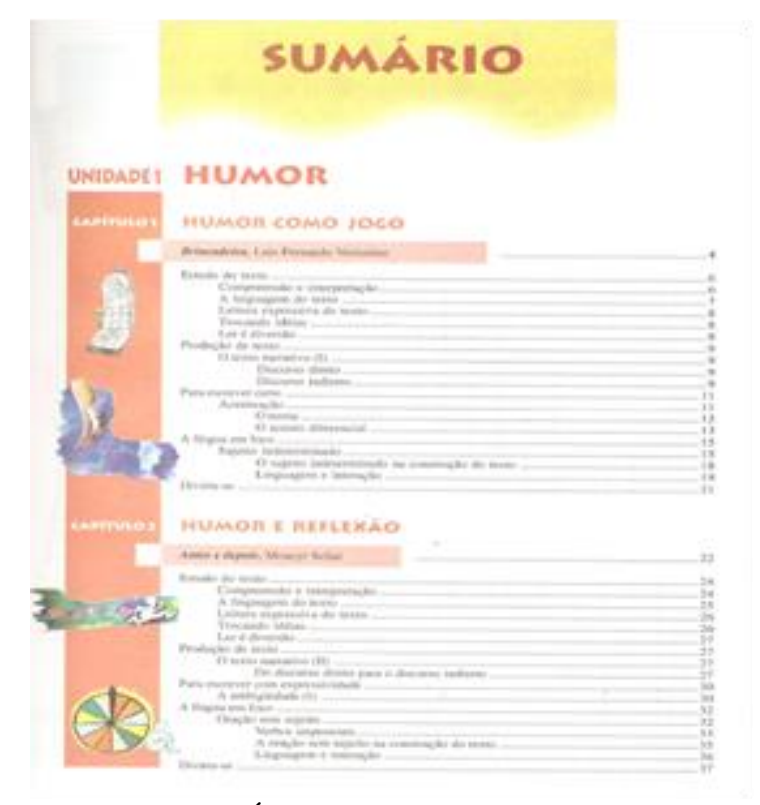

Figura 08 - Índice do Português: Linguagens Fonte: Cereja; Magalhães, 1998

Podemos observar que, diferentemente das décadas anteriores, há, agora, a preocupação de se fornecer ao aluno, e também ao professor, um "retrato" completo do que se vai encontrar no livro, as seções específicas - estudo de texto, produção de texto, para escrever certo, a língua em foco, divirta-se - e o que cada uma vai trabalhar. Não há, portanto, apenas a informação dos textos e dos tópicos gramaticais a serem estudados, como antes. Esse padrão segue, a partir dessa década, nos LDP.

\section{A titulação dos livros didáticos}

Como estamos tomando o Livro Didático de Português como resultado de todo um trabalho conjunto de produção, inserido num contexto sócio-histórico definido, esses livros seguem aquilo que está em vigor em cada momento histórico no que se refere ao ensino de língua materna.

Nessa perspectiva, sua titulação - tomada aqui como os nomes dados a cada coleção 
analisada - merece destaque, pois, como pudemos observar, ela, assim como todos os elementos estruturais vistos anteriormente, também muda para se adaptar a cada novo movimento do ensino de língua materna.

Da mesma forma que os conteúdos que veiculam nos LDP, suas formas, estruturas, organização interna, seus títulos também não são escolhas desvinculadas de todo o processo histórico nos quais os livros circulam e são produzidos. Ao contrário, são escolhas pensadas discursivamente e refletem o momento no qual tiveram/têm vigência. Ou seja, também são reflexos da historicidade latente desses livros e nos remetem a essa história. Como mostra Costa (2000, p. 82): "contemplam o significado global/total do texto produzido e foram elaborados, dialogicamente, na interação verbal real de uso linguístico".

Ainda sobre a importância dos títulos, Travassos (2003) os toma como um elemento de extrema importância para os textos que concretizam os diversos gêneros que circulam em sociedade. Eles possibilitam levantarmos hipóteses, focalizarmos o que esperamos de um texto. Também refletem intenções comunicativas. No caso dos LDP, possibilitam uma visualização da estrutura esperada para esses livros em cada época, a ênfase dada ao ensino de língua materna a partir das concepções vigentes em cada uma. Exercem, portanto, diversas funções, entre elas:

a) Enquadrar o texto cognitiva e semanticamente;

b) Nomear o texto;

c) Despertar o interesse de quem lê;

d) Organizar o texto;

e) Funcionar enunciativamente.

No caso específico do Livro Didático de Português, procuramos observar essas funções a partir dos títulos dos livros característicos de cada época, aqui representadas pelos séculos que nos serviram de base para a caracterização dos livros, isso como forma de darmos uma maior relevância para esse elemento que pode "[...] ser considerado um organizador do texto, que projeta expectativas a respeito do seu conteúdo" (TRAVASSOS, 2003, p. 57). É o que podemos observar no quadro que segue:

Quadro 01: Titulação dos LDP ao longo dos séculos

\begin{tabular}{|l|c|c|}
\hline \multicolumn{1}{|c|}{ TÍTULOS } & TIPOS & PERÍODO/SÉCULOS \\
\hline - Antologia Nacional & & \\
- Livros de Leitura & & \\
- Língua Pátria & Nominais & XXimeiras décadas do século \\
- Português para o Ginásio & & \\
- Contos Pátrios & \\
- A Pátria brasileira & & \\
- Gramática Elementar & & \\
\hline - Estudo Dirigido de & & \\
Português Década de 1970 \\
- Comunicação e Expressão \\
- Trabalho Dirigido de \\
$\begin{array}{l}\text { Português } \\
\text { - Comunicação } \\
\text { - Português através de Textos }\end{array}$ & Nominais \\
\hline - Português: Linguagens & & \\
- Diálogo & & \\
- Linguagem Nova & & \\
-Interação e Transformação & & \\
- Linguagens no século XXI & & Década de 1990/ Dias atuais \\
\hline
\end{tabular}


- Português - uma proposta

de letramento

Fonte: Patriota (2011)

Travassos (2003, p.77) refere-se aos títulos como "[...] um elemento que deve informar sobre o conteúdo do texto e também caracterizá-lo”. Daí o predomínio de títulos nominais entre os LDP. Essa autora esclarece que osnominais são, muitas vezes, os títulos mais usados pois "[...] parecem ser os mais apropriados para exercer o papel informativo, ou seja, são os mais apropriados para veicular informações que expressem o tema principal" (TRAVASSOS, 2003, p. 78) ${ }^{5}$.

Obviamente, os exemplos apresentados no quadro nos oferecem apenas um pequeno universo dos inúmeros títulos de LDP que poderiam ser citados, principalmente a partir da década de 1970, quando a oferta de LDP já se mostrava mais intensa do que nas décadas anteriores (HALLEWELL, 1985).

Porém, esse pequeno universo já nos permite realizarmos algumas importantes leituras sobre esses títulos. Primeiro, podemos perceber neles a estreita relação entre títulos, concepções de língua, período histórico. Nas primeiras décadas do século XX, a ênfase do ensino era no que se convencionou chamar Gramática Tradicional, a busca do uso puro e correto da língua através do estudo de escritores clássicos, tanto da literatura portuguesa, quanto brasileira (PESSANHA, 2004; CARGNELUTTI, 2009).

O foco era a concepção de língua como expressão do pensamento, por isso títulos como Antologia Nacional, Língua Pátria, Gramática Elementar Contos Pátrios eram comuns e já adiantavam os conteúdos oferecidos em cada um. No caso das primeiras décadas do século XX, os LDP eram representados por Seleções de Textos e Gramáticas, pelo menos no nível secundário de ensino, responsáveis por transmitir ao aluno a língua pura e correta a ser "dominada" por eles, seguindo a tríade Retórica, Poética e Gramática (SOARES, 2011). Eram livros que refletiam toda a estrutura escolar vigente nesse período: alunos pertencentes às camadas economicamente privilegiadas e professores advindos dessa camada social (BITTENCOURT, 2008).

Ao chegarmos à década de 1970, todos os fatos históricos trouxeram para foco de estudo a língua não mais como expressão do pensamento, mas como instrumento de comunicação. Isso representou, pelo menos teoricamente, uma nova perspectiva de ensino, com novos conteúdos em evidência, entre eles os clássicos elementos de comunicação.

Toda a estrutura escolar apresentava-se, agora, com novo feitio, novos eram os alunos, novo o perfil dos professores - já sobrecarregados e com formação precária ${ }^{6}$. Isso justifica títulos - também nominais - como Estudo Dirigido de Português, Comunicação e Expressão, Comunicação, Trabalho Dirigido de Português, entre tantos outros ${ }^{7}$.

Resultado das discussões desenvolvidas na década de 1980, os LDP das décadas de

\footnotetext{
5 Além dos nominais, Travassos (2003) ainda apresenta os títulos verbais ou oracionais, preposicionais, adverbiais, adjetivais e interjetivais.

${ }^{6}$ Para entender todo esse processo que muda tão radicalmente o perfil de nossos professores a partir desse período, consideramos importante a colocação de Soares (2001):"nos anos 1950 e 1960 se intensifica o processo de depreciação da função docente: a necessidade de recrutamento mais amplo e menos seletivo de professores, resultado da multiplicação de alunos, vai conduzindo a rebaixamento salarial e, consequentemente, a precárias condições de trabalho, o que obriga os professores a buscar estratégias de facilitação de sua atividade docente uma delas é transferir ao livro a tarefa de preparar aulas e exercícios” (p. 167). Guedes (2006) também traz na obra "A formação do professor de português - que língua vamos ensinar?" uma importante discussão sobre a mudança do perfil dos professores de língua materna frente à nova realidade do ensino pós-democratização. E, muito antes desses, temos o posicionamento de Geraldi (1997) sobre essa questão.

${ }^{7}$ Ressaltamos, no entanto, que apesar de estarmos diante de uma nova concepção de língua, com ênfase nos elementos da comunicação, perspectiva de novos rumos para o ensino de português, ainda predominou nesse período o estudo da nomenclatura gramatical (SOARES, 2011).
} 
1990 até nossos dias atuais são representantes do que se convencionou chamar "virada pragmática" (PRETI, 1998; RANGEL, 2002). Ou seja, a meta de ensino agora não se encontra mais centrada na gramática em si, mas está centrada na concepção de língua como interação.

Isso representou a possibilidade de se trazer para os LDP temas até então, digamos "proibidos", como a questão da variação linguística, textos representativos do nosso cotidiano - fruto da Teoria dos Gêneros Textuais - a oralidade em seu estudo efetivo, não apenas reduzida a leituras dramáticas. Enfim, são LDP que, como afirma Rangel (2002, p. 19) "precisará enfrentar os novos objetos didáticos do ensino de língua materna".

Daí títulos como Português: Linguagens, Diálogo, Linguagens no século XXI, Interação e Transformação, Português: uma proposta de letramento e tantos outros que fazem referência a essa nova forma de se conceber a língua e, por consequência, os novos conteúdos de ensino advindos dessa concepção voltada para os usos efetivos da linguagem em situações reais de interação (VAL, 2009).

\section{Considerações finais}

Enfim, pelo exposto, podemos perceber todos os itens estruturais dos LDP aqui analisados, como elementos que revelam a ênfase dada ao ensino de língua materna em cada época, reforçando, com isso, a intrínseca relação entre as concepções de língua/ensino de cada momento histórico com o propósito/finalidade do LDP em cada um desses momentos. Como vemos na síntese das principais mudanças aqui analisadas apresentadas no quadro abaixo:

Quadro 02: Demonstrativo das principais mudanças estruturais da TD Livro Didático de Português

\begin{tabular}{|c|c|c|c|}
\hline \multirow[t]{2}{*}{ PERÍODO } & \multicolumn{3}{|c|}{ MUDANÇAS } \\
\hline & FORMATOS & CAPAS & $\begin{array}{c}\text { ORGANIZAÇÃOO } \\
\text { INTERNA }\end{array}$ \\
\hline $\begin{array}{l}\text { Primeiras décadas do } \\
\text { século XX }\end{array}$ & $17 \times 11 \mathrm{~cm}$ & $\begin{array}{l}\text { - Sóbrias } \\
\text { - Na sua maioria, sem } \\
\text { cor }\end{array}$ & $\begin{array}{l}\text { - Seleta de textos em } \\
\text { prosa e verso. }\end{array}$ \\
\hline Década de 1970 & $21 \times 14 \mathrm{~cm}$ & $\begin{array}{l}\text { - Coloridas } \\
\text { - Ilustradas }\end{array}$ & $\begin{array}{l}\text { - Textos e gramática } \\
\text { num só livro, mas em } \\
\text { partes separadas. }\end{array}$ \\
\hline $\begin{array}{l}\text { Décadas } \\
\text { contemporâneas }\end{array}$ & $28 \times 20 \mathrm{~cm}$ & $\begin{array}{l}\text { - Coloridas } \\
\text { - Muito ilustradas } \\
\text { - Referência às muitas } \\
\text { linguagens }\end{array}$ & $\begin{array}{l}\text { - Textos e gramática } \\
\text { num só livro, com } \\
\text { estudo integrado ao } \\
\text { longo das unidades. }\end{array}$ \\
\hline
\end{tabular}

Fonte: Patriota (2001)

No que se refere a esses livros, o que todos os traços de mudanças e permanências em capas, tamanhos e organização interna, e títulos, nos revelaram que eles passaram por muitas alterações ao longo do tempo, adaptando-se às sucessivas mudanças sócio-históricas vistas anteriormente. No entanto, permaneceu a finalidade comunicativa predominante desses livros: a organização sistemática dos conteúdos autorizados ao ensino da língua materna em cada época.

Ou seja, mudaram os formatos, as capas, a organização interna, porém os LDP não deixaram de existir, nem de serem reconhecidos como tais devido a essas mudanças ao longo de sua história constitutiva. Tomando de empréstimo as palavras de Gomes (2007, p. 157): "todas as modificações organizacionais aqui pontuadas revelam os processos de adaptação desses livros a sucessivos contextos, sem provocar a interrupção de seu percurso". Em outras 
palavras, o Livro Didático de Português continua sendo reconhecido como tal, independente de suas alterações visual-tipográficas ou mesmo de concepções e conteúdos que veicula.

\section{Referências}

BARRETO, F.; LAET, C. de. Anthologia Nacional. São Paulo: Paulo de Azevedo \& CIA, 1921.

BATISTA, A. A.G. O processo de escolha de livros: O que dizem os professores. In: BATISTA, A. A . G.; VAL, M. da G. C. (Orgs.). Livros de alfabetização e de português: os professores e suas escolhas. Belo Horizonte: Ceale/Autêntica, 2004, p. 29-74.

BATISTA, A. A. G.; ROJO, R. Livros escolares no Brasil: a produção científica. In: VAL, M. da G. C.; MARCUSCHI, B. (Orgs.). Livros didáticos de língua portuguesa: letramento e cidadania. Belo Horizonte: Ceale/Autêntica, 2005, p. 13-46.

BATISTA, A. A. G.; GALVÃO, A. M. de O.; KLINKE, K. Livros escolares de leitura: uma morfologia. Revista Brasileira de Educação, nº 20, maio/junho/agosto, 2002.

BEZERRA, M. A. Reflexões sobre o livro didático de português. Revista Ariús, Campina Grande: UFPB/CH, Janeiro/Dezembro, 1993, p. 65-70.

BITTENCOURT, C. Livro didático e saber escolar - 1810-1910. Belo Horizonte: Autêntica, 2008.

CARGNELUTTI, J. Considerações sobre a história do ensino da língua portuguesa no Brasil: um livro didático da década de 1960. Estudos linguísticos, São Paulo, 38, maio-agosto, 2009, p. 123-133.

CARVAlHO, F. de. Primeiro Livro de Leitura. 59. ed. Rio de Janeiro: Francisco Alves e CIA, 1911.

CEREJA, W. R.; MAGAlHÃES, T. C. Português: Linguagens. $5^{\mathrm{a}}$ a $8^{\mathrm{a}}$ séries. São Paulo: Atual, 1998.

COSCARELli, C. V.; SANTOS, E. M. dos. O livro didático como agente do letramento digital. In: VAL, M. da G. C. Alfabetização e língua portuguesa-livros didáticos e práticas pedagógicas. Belo Horizonte: CEALE/ Autêntica, 2009, p. 171-188.

COSTA, S.R. A construção de títulos em gêneros diversos: um processo discursivo polifônico e plurissêmico. In: ROJO, R. A prática de linguagem em sala de aula - praticando os PCNs. São Paulo: Mercado de Letras, 2000 p. 67- 90.

DIONÍSIO, Â. P.; BEZERRA, M. A. O livro didático de português - múltiplos olhares. Rio de Janeiro: Lucerna, 2002.

FARIAS, W. Sentidos da língua e do sujeito a ensinar-aprender no Brasil: o discurso da coleção Novo Manual de Língua Portuguesa F.T.D. João Pessoa, 2010. 280 f. Tese (Doutorado em Linguística). Universidade Federal da Paraíba. 
FERREIRA, R. M. Estudo Dirigido de Português. $1^{\text {a }}$ e $2^{\mathrm{a}}$ série ginasial. São Paulo: Ática, 1970.

FREITAG, B. et al. O livro didático em questão. São Paulo: Cortez, 1989.

GOMES, V. Traços de mudanças e de permanência em editoriais de jornais pernambucanos: da forma ao sentido. Recife, 2007. 313 f. Tese (Doutorado em Linguística). Universidade Federal de Pernambuco.

HALLEWELL, L. O Livro no Brasil. São Paulo: Editora da Universidade de São Paulo, 1985.

LINS, O. Do ideal e da glória - problemas inculturais brasileiros. São Paulo: Summus Editorial, 1977.

MARCUSCHI, L. A. Gêneros textuais emergentes no contexto da tecnologia digital. In: ; XAVIER, A. C. (Orgs.). Hipertexto e gêneros digitais. Rio de Janeiro: Lucerna, 2005, p. 13-67.

MATTOS e SILVA, R. V.; SOUZA, E. H. P. M de. A escolarização relacionada à demografia na província da Bahia no século XIX. In: AGUILERA, V. (Org.). Para a história do português brasileiro. VI Seminário do PHPB. Londrina: UEL, 2009.

OLIVEIRA, J. B. A. et al. A política do livro didático. São Paulo: Summus, 1984.

OLIVEIRA, M. R.; WILSON, V. Linguística e ensino. In: MARTELLOTA, M. (Org.). Manual de Linguística. São Paulo: Contexto, 2008, p. 235-242.

OLIVEIRA, C. R.G. A. de.; SOUZA, R. F. de. As faces do Livro de Leitura. Disponível em: <www.sbhe.org.br/novo/congressos/cbhe2>. Acesso em: 21 set. 2011.

PATRIOTA, M. L. A Tradição Discursiva no Livro Didático de Português: mudanças e permanências ao longo dos séculos XX e XXI. João Pessoa, 2011. 218 f. Tese (Doutorado em Linguística). Universidade Federal da Paraíba.

PESSANHA, E. C. et al. Da história das disciplinas escolares à história da cultura escolar: uma trajetória de pesquisa. Revista Brasileira de Educação, Rio de Janeiro, no 27, set./dez., 2004, p. 57-69.

PIETRI, E. de. A formação do professor de língua portuguesa e as propostas de mudança em concepções de linguagem e de ensino. Disponível em: 〈www.cce.ufsc.br〉. Acesso em: 17 jul. 2008.

PRETI, D. A gíria na sociedade contemporânea. In: VALENTE, A. C. (org.). Língua, linguística e literatura: uma integração para o ensino. Rio de Janeiro: EDUERJ, 1998, p. 119127 
RANGEL, E. Livro didático de língua portuguesa: o retorno do recalcado. In: DIONÍSIO, Â. P.; BEZERRA, M. A. O livro didático de português - múltiplos olhares. Rio de Janeiro: Lucerna, 2002, p. 13-20.

RAZZINI, M. de P. G. O espelho da nação: a Antologia Nacional e o ensino de Português e de Literatura (1838-1970). Campinas, 2001. 219 f. Tese (Doutorado em Letras). Universidade Estadual de Campinas.

SOARES, M. B. Que professor de português queremos formar? Disponível em: <www.filologia.org.br/viiisenefil/07>. Acesso em: 09 fev. 2011.

Português na escola - história de uma disciplina curricular. In: BAGNO, M. (Org.). Linguística da norma. São Paulo: Loyola, 2002, p. 155-178.

. Um olhar sobre o livro didático. Revista Presença Pedagógica. Editora Dimensão, v.2, nº 12, nov./dez., 1996.

SILVA, A. L. da. Livros de leitura de Felisberto de Carvalho e Mario da Veiga Cabral: usos e significados. Disponível em: <www.alb.com.br/arquivomorto/edicoes_anteriores/anais17/COLE_3013>. Acesso em: 21 set. 2011.

SOUSA, M. E. V. de. Política de leitura para o ensino médio: o PNLEM e o LD. Anais do CIPLA, 2006, p. 224-230.

TRAVASSOS, T. Títulos, para que os quero? In: DIONÍSIO, A. P.; BEZERRA, N. da S. (Orgs.). Tecendo textos, construindo experiências. Rio de Janeiro: Lucerna, 2003, p. 55-80.

VAL, M. da G. C. Alfabetização e língua portuguesa - livros didáticos e práticas pedagógicas. Belo Horizonte: CEALE/ Autêntica, 2009.

Recebido em: julho de 2015.

Aprovado em: setembro 2015. 